June 2019

\title{
Contemporary Art and Historical Archives: Collaborations and Convergences in a Digital Multicultural Age
}

Suzanne S. LaPierre

University of South Carolina, Columbia, summerslapierre@gmail.com

Follow this and additional works at: https://scholarworks.sjsu.edu/ischoolsrj

Part of the Archival Science Commons, Collection Development and Management Commons, Interdisciplinary Arts and Media Commons, Museum Studies Commons, Scholarly Communication Commons, and the Scholarly Publishing Commons

\section{Acknowledgements}

The author would like to acknowledge Edward Blessing, Interim Head of User Services and Interim Curator of Published Materials at South Caroliniana Library, for his feedback on an early version of this paper. She would also like to acknowledge the editors and reviewers of this Journal for their astute suggestions which contributed to the final version of this piece.

\section{Recommended Citation}

LaPierre, S. S. (2019). Contemporary Art and Historical Archives: Collaborations and Convergences in a Digital Multicultural Age. School of Information Student Research Journal, 9(1). https://doi.org/10.31979/ 2575-2499.090104 Retrieved from https://scholarworks.sjsu.edu/ischoolsrj/vol9/iss1/4

This article is brought to you by the open access Journals at SJSU ScholarWorks. It has been accepted for inclusion in School of Information Student Research Journal by an authorized administrator of SJSU ScholarWorks. For more information, please contact scholarworks@sjsu.edu. 


\title{
Contemporary Art and Historical Archives: Collaborations and Convergences in a Digital Multicultural Age
}

\begin{abstract}
Literature illuminating the relationship between contemporary art and historical archives around the turn of the twenty-first century and how these interactions inform the evolution of archives in a digital multicultural age is the topic of this review. The literature reveals the extent to which art has been a means for members of marginalized groups to address their representation in historical archives, and also a means for archives to connect with a broader audience. Collaborations between artists and historical archives add new dimension to the debate about the nature of the archive as a creation in and of itself, and in turn the question of whether participatory culture may be a necessary component in achieving more complete representation of all segments of the community. Types of relationships explored in this review include: the questioning of and re-imagining of the archive by artists, particularly those from marginalized groups; the blending of art and digital archives; and how such collaborations have informed the mission and practical concerns of archives. As digitization leads to increasing convergence of previously distinct cultural heritage collections and enthusiasm for participatory platforms accelerates, interactions between individual artists, people from marginalized communities, and GLAM (galleries, libraries, archives and museums) will continue to evolve and expand. From this literature review emerge observations about prior collaborations from around the world as they inform future developments.
\end{abstract}

\section{Keywords}

diversity, outreach, contemporary art, historical archives, museums, libraries, galleries, artists, GLAM, LAM, marginalized groups, exhibit design, conceptual art, contemporary culture, multiculturalism, historical narrative, collaborations, partnerships, participatory culture, non-custodial archives, inclusivity, installation art

\section{Acknowledgements}

The author would like to acknowledge Edward Blessing, Interim Head of User Services and Interim Curator of Published Materials at South Caroliniana Library, for his feedback on an early version of this paper. She would also like to acknowledge the editors and reviewers of this Journal for their astute suggestions which contributed to the final version of this piece.

\section{About Author}

Suzanne Summers LaPierre holds a MLIS from University of South Carolina, Columbia, a MA in Museum Studies from The George Washington University and a BFA in Painting from Rhode Island School of Design. Her career has included working in galleries, libraries, archives, and museums (GLAM). Current research interests include media literacy initiatives and GLAM collaboration. She currently works in Information Services for Fairfax County Public Library in Virginia. 
Contemporary archives are undergoing significant changes brought about by digitalization and increased inclusion of diverse perspectives. While much has been written on collaborations of artists with art museums and galleries, this review examines collaborations between artists and historical archives as indicative of significant developments in the field. A review of the literature reveals the extent to which the interaction between contemporary artists and historical archives has contributed to diversification of the historical narrative, as art has often been a means of questioning and re-imagining the archive by people from marginalized groups. This literature review explores the core question: How do interactions between contemporary art and turn-of-the-21st century archives inform the evolution of historical archives in a digital multicultural age?

Art has been a means for members of marginalized communities to address their representation in historical archives, and also a means for archives to connect with new audiences. Exploring literature and collaborations from members of the art community reveals the extent to which art has empowered individuals, particularly those from marginalized groups, to correct their perceived absence or misrepresentation in traditional cultural institutions. Literature generated by archivists and librarians on the practical aspects of collaboration with artists reveals challenges including the time and effort involved in coordination, reconciling differing expectations and methods, along with vital benefits such as expanding collections, broadening the historic record, and increasing relevance to the community.

Collaborations between artists and historical archives highlight the extent to which the archive is a creation in and of itself. As a human creation, the archive reflects the experience and perspective of the creators; therefore, only by enabling a diverse multiplicity of participants can the historical record be truly representative of the multi-faceted world in which we live. Earlier collaborative efforts between artists and archivists foreshadowed the current participatory culture movement which is enabling further diversification of the historical record by allowing more involvement of individuals from underrepresented groups.

Use of the term "contemporary art" in this literature review refers to the time frame during which the art was created rather than a particular method or style of art. That is, the artwork was created current to the archive-related project discussed in the literature. The section "Collaborations and Convergences" examines literature on art projects since the 1990s in which the dominant narrative and its archival representation were called into question. These projects often took the form of conceptual art installations within cultural heritage institutions. The section "Practical Challenges and Benefits" reveals experiences of collaboration from the perspective of archivists. In these examples the artwork involved, while contemporary in time frame, often consists of more traditional materials such as painting and types such as regional, folk, and "outsider" or "visionary" art. "Digital Overlap" explores the extent to which digital methods have accelerated the existing overlap between collecting and creating spheres. It includes some examples in which both art and archive exist entirely in digital format. The conclusion looks forward, positing that progress towards more inclusive representation in the historic record will continue as participatory 
culture becomes more integral to GLAM (galleries, libraries, archives and museums).

\section{Literature Review}

\section{Collaborations and Convergences}

Many conceptual artists have worked with archives as a theme and source, questioning how historical collections are acquired and organized, and the narratives that emerge from those arrangements. From the literature on these projects emerges theory about the construction of archives and the historical narrative that archives represent and co-create. Much of the literature also touches upon the efforts of archivists to invite, accommodate and even absorb new perspectives. Many of the most thought-provoking projects have involved artists from marginalized groups expressing a sense of alienation and asserting a presence in the archive.

In a seminal 1992 interpretation of the collection of The Maryland Historical Society (MdHS) from an African-American perspective, artist Fred Wilson created an installation by re-juxtaposing objects and documents from the collection. The title of the exhibition, Mining the Museum, reflected the processmining the collection for items, most of which were in storage as well as the emerging theme - a representation of history that felt more "mine" to the artist than that previously presented. Wilson displayed a pair of shackles amid fine silver serving pieces and a whipping post among elegant upholstered furniture. He placed a Klan hood in a vintage baby carriage and spotlighted an estate log listing enslaved humans alongside livestock, including an elderly woman named Hannah who was valued at one dollar (Wilson, Corrin \& Contemporary, 1994). Wilson created powerful statements merely by changing the arrangement of the collection, raising the question - how neutral is our telling of history? Are archivists and curators creating narrative as they acquire and arrange items? Was Wilson's narrative any more or less valid than that presented previously?

In "How Mining the Museum Changed the Art World" (2017), Maryland Institute College of Art curator Kerr Houston wrote that Wilson's installation permanently changed the way MdHS presented their collection. For example, Wilson added a spotlight illuminating the image of an enslaved boy in the shadows of a portrait of a white child. The MdHS now recognizes the enslaved child as well as the white child in its labeling and cataloging of the painting. Wilson's project demonstrated that curating, archiving and exhibit design are powerful acts of narrative, blurring the line between the artist and the archivist/ curator.

Wilson's work was an intervention by invitation, however. The project was rooted in then-director Charles Lyle's desire to expand the relevance of the MdHS and garner increased engagement from the public, particularly from members of the community who may previously not have felt represented (Ciscle \& Lyle, 1994). MdHS is located in Baltimore, a city with a majority-black population. Visitation surged during the exhibit and also ignited some controversy among those who found it inflammatory (Ciscle \& Lyle, 1994; Houston, 2017; 
Wilson, Corrin \& Contemporary, 1994). Even the exhibition catalog was an example of more inclusive practices: employing a form of low-tech participatory culture, it included input from docents and audience members in addition to that of curators and historians (Wilson, Corrin \& Contemporary 1994).

Wilson's pivotal creation was facilitated by an early 1990s identity crisis among cultural heritage institutions, marked by growing realization of the need for deeper inclusivity and outreach (Corrin, 1994; Ciscle \& Lyle, 1994). While there were several projects involving the de-mystification of museums in the late 1980s and early 1990s, most involved art museums rather than historical collections, and Wilson's was unique in its direct confrontation of racial issues (Corrin, 1994). Mining the Museum (1992) paved the way for similar projects that would specifically address marginalization, and it foreshadowed some of the concerns integral to the current participatory culture movement and digital GLAM.

While Wilson highlighted an African-American perspective on the MdHS, Susan Hiller's 1994 installation at the Freud Museum in London projected a contemporary American woman's perspective on Freud's living quarters and collections. In "Working Through Objects" (2006), Hiller, whose background in anthropology preceded her art career, explained how she grouped objects in boxes, adding titles and annotations to provide narrative to otherwise disparate items, describing her project as similar to an archeological dig or psychoanalysis, with layers to be excavated and reconstructed (Hiller, 2006). Rejecting the notion of objectivity, she stated that people have a choice among "these histories and fictions" (p. 44). In one piece she combined seemingly-innocuous creamers shaped like cows with a photograph of a Western cowgirl/outlaw brandishing a gun with Freudian swagger. "Cowgirl" is an ironic title she explains, because "cow" is an insulting term for a woman in England. Hiller described this piece and its context within the Freud Museum as "a way of dealing with sexual insult...there was a particular pleasure for me in situating this in the house of the father" (pp. 45-46). In other pieces, she incorporated words from many languages "to give a sense of being outside the discourse" (p. 47).

In "Contemporary Art, the Archives and Curatorship: Possible Dialogs" (2018), Brazilian curator and professor of art Priscela Arantes explores contemporary Brazilian artists who have drawn on content from historical archives to interpret the way history is told, as well as those whose conceptual art re-imagines the way archives are constructed, classified and presented. Among the work she discusses is that of Rosangela Renno, who purchased collections of photographs from the 19th century through the 1980's and exhibited them arranged by color, emphasizing how the organization of material changes the manner in which it is perceived and interpreted. Arantes also discusses the work of Mabe Bethonico as an example of "problemizing the archive" (pp. 457-459). The artist was invited to develop a project for the Museu de Arte da Pampulha in 2004 and chose to work with material from the museum's database rather than objects from its collection. Bethonico's displays created from the raw data highlighted the cataloging process as representing a choice of narrative. Arantes' piece concluded with observations on the impact of contemporary art as it calls 
upon museums to reflect on their practices regarding collections and archives management, and their role as democratic spaces. The fact that the selected artwork critiquing collection methods was created by women, whose place in traditional art museums has historically been that of subject matter rather than creators, adds an unspoken dimension of outsider-ness that Arantes, perhaps deliberately, does not address directly in her essay.

In the book The Archive (MIT Press, 2006), editor and art historian Charles Merewether compiled essays and excerpts on the theme of archives as explored by theorists and artists since the 1960s as a means of exploring individual and collective memories and histories. Among the projects Merewether discussed in his introduction to The Archive is that of the Arab Image Foundation, created by photographers in 1996 in Beirut to collect and preserve images of the Arab world. The group collects family albums, studio photography, and other existing imagery to "map the forgotten or suppressed micro-histories of twentiethcentury Arabic culture" (Merewether, 2006, p.17). Founded by Arab photographers to preserve examples of their art and culture, this project represents an interesting case of artists-turned-archivists. By creating work for the archive as well as collecting, the photographers are merging the endeavors of artists and archivists. However, the cross-over goes both ways. In his essay for The Archive, "Photographic Documents/ Excavation as Art" (2006), photographer/ videographer and co-founder of the Arab Image Foundation Akram Zaatari describes the incorporation of historical documents in his art. He collects photographs, documents, notebooks, email attachments and testimonies from areas of conflict in the Arab world and uses them in his video work, essentially building an archive into the artwork to inform the issues he is exploring creatively. The Archive includes many such examples in which the distinction between artist and archivist is blurred.

Zaatari and the other artists participating in the Arab Image Foundation (Merewether, 2006; Zaatari, 2006) have something in common with Brazilian artists such as Renno (Arantes, 2018). These artists' work uses techniques of the archivist in promoting the value of imagery produced by common people documenting ordinary lives, rather than that of more notable figures that historians might traditionally study, collect and value more highly. In arranging and presenting such items the artists assert the importance of overlooked voices in telling a fuller story.

While much of the work written about in The Archive leans esoteric, a reinterpretation of historical records in art that has been widely embraced by popular culture is illuminated in "'Who Lives, Who Dies, Who Tells Your Story': The Use and Representation of Records in Hamilton: An American Musical" (Madison, 2017). The musical Hamilton explores the construction of narrative via the documentation of history, inviting audiences to reflect on the process with the questioning refrain: "who tells your story?" Documents appear throughout as props, plot devices, and subjects. One of Hamilton's claims to fame is having been the writer of some of the most valuable documents in American history. While exploring this widely recognized narrative, playwright Lin-Manuel Miranda also frequently refers to Hamilton's outsider status as a bastard, orphan, 
and immigrant. He alludes to the slaves hidden behind the scenes of history, writing the music with a rap beat for a majority African-American cast, bringing historically suppressed voices to the forefront, at least symbolically. Miranda also delves into lesser known stories such as that of Hamilton's wife Eliza, who has a large role to play in the record-keeping aspect of Hamilton: in one scene she is seen burning letters to prevent future generations from speculating on the content, whereas in the finale she is lauded for her labor gathering Hamilton's work for publication, including recording the stories of unsung men who fought alongside her husband in battle. Through selective collection of records, Eliza is the archivist of Hamilton's story (Madison, 2017). By thoroughly footnoting the many ways documents are incorporated into the play's meaning and presentation, Madison adds to the question of the archive as an act of narration and art as a reexamination of that narrative (Hiller, 2006; Madison, 2017; Wilson, Corrin \& Contemporary, 1994).

\section{Digital Overlap}

As both art and archives have become increasingly digitalized and internetaccessible, some overlaps have occurred that enable further participation from artists previously outside of mainstream discourse, including those from underrepresented groups. However, changes brought about by the rapidly evolving digital landscape may also lead to potential misinterpretations, whether in terms of cultural misunderstandings or format-related altering of the original intentions of an art work. Digitization and web accessibility also serve to further blur the distinctions between art and archive.

Some of the attending quandaries are explored in literature about the archiving of unrealized or ephemeral contemporary art projects. In this case the very artwork itself occupies marginalized status as projects that have been rejected and/or are outside the traditional purview of collecting organizations. When the conceptual art movement began in the 1960s, art was created that had no lasting object attached to it; thus the record of the art often became its tangible representation. Documentation of the art process became the art (Arantes, 2018). A concrete example of this process is MoRE, a digital archive founded in 2012 consisting of documentation of never-produced art projects from the 1950's onwards. As described in "MoRE, an Archive of Signs and Traces of Artistic Practices: Creating a Tool for Research in Contemporary Art and Curatorial Practices," "the primary task of the curators is to reconstruct a working process, and the methodologies and ideologies behind it, through the combined codified tools of the archivist and art historian (cataloging rules, controlled vocabulary, and thesauri)" (Zanella, Bignotti, Modena \& Scotti, 2015, p. 67). While many contemporary conceptual artists have explored the idea of the archive as art-a creation in and of itself - the MoRE project explores the idea of art as archive. Are the unrealized MoRE projects art, but art that exists only in the form of a digital archive? Is the archive the art?

Concerns regarding the creation of documentary surrogates for works of ephemeral contemporary art are also explored by archivist Katrina Windon in 
"The Right to Decay with Dignity: Documentation and the Negotiation between an Artist's Sanction and the Cultural Interest" (2012). This essay examines considerations surrounding the preservation of surrogate documents for art projects-—whether textual, audio-visual, or material — as they pertain to the intentions of the artist and the integrity of the art work. Surrogates may be created by the artist, the cultural institution acquiring the work, or a third party. Windon emphasizes the importance of careful planning of the documentation process from the point of acquisition because the manner in which surrogates are produced and organized impacts the future interpretation of the art. If the process of archiving the art becomes enmeshed in the perception of the art and its essence as perceived by future viewers, this represents a blurring of the boundary between art-making and archiving as separate processes (Windon, 2012; Zanella et al., 2015).

The strong arguments made for the importance of the surrogate in the future interpretation of art (Arantes, 2018; Windon, 2012) bolster the concept that participatory culture is necessary for marginalized communities to achieve accurate archival representation. While any artist runs the risk of having their work misinterpreted, if the artwork in question was created by an artist from a marginalized group, it is reasonable to question whether archival staff - in which members of mainstream society are traditionally over-represented and members of the marginalized group in question may be totally absent - may not accurately interpret and represent the work even when acting with the best of intentions. This is an important factor to consider when evaluating production and preservation of surrogates, digital or otherwise (Arantes, 2018; Windon, 2012). Participatory methods of archiving, including non-custodial archiving and crowdsourcing, enable input from members of groups typically underrepresented in the staff of cultural heritage institutions (Schreiner \& de los Reyes, 2016).

\section{Practical Challenges and Benefits}

On a more prosaic level, what does the relationship between art and archives mean in terms of bridging the archives with its community, and contributing to core efforts such as acquisitions and research? Several academics and professionals in the field have written about initiatives in which interactions between artists and archivists lead to enhanced collections and stronger community relations, particularly with marginalized segments of the community (Post, 2017; Schreiner \& de los Reyes, 2016). Their work highlights some of the challenges as well as benefits of such collaborations.

For example, the importance of, and special considerations surrounding, the practice of archiving materials pertaining to regionally significant and selftaught artists is explored in "Ensuring the Legacy of Self-Taught and Local Artists: A Collaborative Framework for Preserving Artists' Archives" (Post, 2017). In this piece, Colin Post, a doctoral student at University of North Carolina Chapel Hill (UNC), wrote about a project designed to create a sustainable collaborative arrangement between a significant local painter, Cornelio Campos, and the Durham County Library. The case study highlights the challenges and benefits of working collaboratively with a local artist to organize and preserve his 
materials for the archive, as well as for his personal use. Some of Campos' work was also made digitally available to expand access to the community. Challenges included a great deal of time spent in hands-on cooperation and communication as well as negotiating copyright and intellectual control issues. Benefits included preserving an important part of the community's cultural heritage and developing a stronger relationship between the library and the Mexican-American and arts communities.

Post (2017) extrapolated from this case a framework to provide guidance to local artists in preserving and organizing their personal materials, whether or not those may eventually be acquired by the archive. This type of outreach is of particular benefit to those sometimes known as "outsider" artists, whose work might not meet benchmarks considered valuable by current collecting organizations. Overall, the project demonstrated how a cultural institution may enrich its collection while also becoming more inclusive and accessible to multiple under-represent segments of its community. While working with Campos helped bridge the archive with its Mexican-American community, the project is a reminder that marginalized groups can also include those of under-privileged social classes or those representing currently unpopular viewpoints (Merewether, 2006; Post, 2017; Zaatari, 2006.)

Another example of the arts bridging traditional archives with underrepresented communities is explained in "Social Practices Artists in the Archive: Collaborative Strategies for Documentation" (Schreiner \& de los Reyes, 2016). The authors describe a 2015 project which utilized the arts and postcustodial digital archiving techniques to expand documentation of the FilipinoAmerican community in Queens, New York. Queens Memory, the Queens Library local history project coordinated by Maggie Schreiner, collaborated with My Baryo My Borough, a project conceived by artist Claro de los Reyes, and the local Filipino-American community, to create a collaborative collection made public via the website queensmemory.org. The process included creating artsbased events to attract community members, collecting oral histories, and photographing culturally significant items belonging to the community for inclusion in the digital archives. This project helped foster trust and engagement with the community while building the archival record of a significantly underrepresented group.

Both the North Carolina and New York projects represent innovative use of the arts as part of community outreach, expanding collections pertaining to underrepresented groups in the area while building trust and interest among community members. The artists involved were local members of the community, in contrast to some of the collaborations outlined in the first section of this literature review. Literature generated by archivists tends to be more prescriptive, and that from the arts field more theoretical; however, a common theme is the use of the arts and participatory culture as a means to increase diversity represented in the archives as well as reaching a broader diversity of users.

In order for such collaborations to occur, archivists must interact with artists, a group of people who by nature of their work represent a group that is outside of traditional norms when it comes to their use of the archives (Lazar, 
2013; Mulligan, 2011). Artists have unique ways of utilizing archives that may present challenges but that may be better facilitated by archivists through foresight, understanding and preparation, as reference librarian Lisa Lazar of the Bierce Library, University of Akron, Ohio explains in "Hidden Gems: Creative Artists and Historical Society Libraries and Archives" (2013). This piece explores the benefits of artists making use of historical archives and explains why those collections may be under-utilized by this group. While there are other more general studies of the information-seeking habits of artists, Lazar's piece is tailored for those in historical societies and archives who may be interested in making their collections more accessible to artists. In her analysis, Lazar notes a significant lack of literature regarding the information-seeking habits of artists outside the realm of visual arts, such as musicians and theatrical artists. This article, like that of many archivists (Lazar, 2013; Mulligan, 2011; Post, 2016), is of prescriptive and practical use for those in the archives field, as opposed to the more theoretical aspects of artists' use of archival collections explored by many in the arts field (Arantes, 2018; Hiller, 2006; Merewether, 2006; Wilson, Corrin \& Contemporary, 1994).

\section{Conclusion}

While much has been written on the relationship between art and archives in general, there is relatively little literature specific to the relationship between contemporary art and historical archives; however, this later type of collaboration is illuminating when it comes to improved representation of marginalized groups within the dominant narrative. Literature from those in the art, art history, and art curation fields tends to focus on the theoretical and conceptual vision of projects, while literature from archivists and librarians tends to be prescriptive and anecdotal, deriving practical guidance from case studies. Wider empirical studies on the overall history and impact of such collaborations is lacking but would be of value in informing current developments and potential future directions. While the compilation volume The Archive (2006) gives broad perspective on such projects from the art world's point of view, it was published over a decade ago and thus lacks coverage of more recent projects.

The future of collaborations between artists and cultural heritage organizations is bound to be impacted greatly by digital formats and online participatory platforms. Digitization is bringing together previously siloed cultural institutions internationally in what is becoming known as LAM (libraries, archives and museums) or GLAM (galleries, libraries, archives and museum) collaboration (Marcum, 2014). The digital presence of GLAM as it pertains to the inclusion of marginalized communities on an international level and the challenges attending those efforts are explored in "Stepping Beyond Libraries: The Changing Orientation in Global GLAM-Wiki” (Stinson, Fauconnier \& Wyatt, 2018). The advent and expansion of GLAM participatory platforms will likely make greater collaboration possible among individual artists and cultural heritage institutions; however, not much literature yet exists on this topic.

Existing literature reveals the value of expanding the archives' collection 
and outreach as a means of attaining a more inclusive and thereby broader and more accurate historical narrative. A comprehensive study of late twentieth and early twenty-first century collaborations between artists and archives, particularly as they informed the representation of marginalized groups in historical archives, would benefit the field as a foreshadowing of current participatory culture issues. The material covered in this literature review does not include examples specific to LGBTQ+ representation; the author suggests this as a topic for future development as content is rapidly emerging in this area. Further research on the growth of GLAM and participatory culture as means by which members of marginalized groups are achieving fuller representation in archives would also be illuminating. Analysis of how the merging of art and historical archives via digital platforms served as a precursor to current GLAM developments would be relevant in grounding the future outlook.

Overall, collaboration between archivists and artists, particularly those from marginalized groups, has furthered examination of the narratives that are constructed via methods of acquisition, organization, and presentation of collections. These efforts have helped remediate the long-standing absence or misrepresentation of marginalized groups in historic collections. Digital methods and platforms such as post-custodial collection methods and crowdsourcing have also played a role in increasing inclusivity which, in turn, creates a richer and more complete historical record. As archiving methods become more participatory, the line between art and archives continues to blur. With openness to ever-expanding methods of collecting, curation and communication, archives of the future may be more relevant than ever to the multifaceted communities they serve and represent. 


\section{References}

Arantes, P. (2018). Contemporary art, the archive and curatorship: Possible dialogues. Curator, 61(3), 449-468. Retrieved from https://doi.org/10.1111/cura.12266

Ciscle, G. \& Lyle, C. (1994). Foreward. In F. Wilson, L. G. Corrin \& Contemporary (Eds.), Mining the Museum: An Installation by Fred Wilson (pp/ lxxi-lxxii). Baltimore, MD: The Contemporary.

Corrin, L. G. (1994). Mining the Museum: Artists Look at Museums, Museums Look at Themselves. (1994). In F. Wilson, L. G. Corrin \& Contemporary (Eds.), Mining the Museum: An Installation by Fred Wilson (pp 1-22). Baltimore, MD: The Contemporary.

Hiller, S. (2006). Working through objects// 1994. In C. Merewether (Ed.), The Archive (pp. 41-48). Cambridge, MA: The MIT Press.

Houston, K. (2017). How mining the museum changed the art world. B 'More Art. Retrieved from http://www.bmoreart.com/2017/05/how-mining-themuseum-changed-the-art-world.html

Lazar, L. (2013). Hidden gems: Creative artists and historical society libraries and archives. The Reference Librarian, 54, 263-279. Retrieved from http://doi.org/10.1080/02763877.2013.806237

Madison, K. (2017). “'Who lives, who dies, who tells your story"': The use and representation of records in Hamilton: An American musical." The American Archivist, 80(1), 53-81.

Marcum, D. (2014). Libraries, archives, museums: Coming back together? Information \& Culture: A Journal of History, 49(1), 74-89.

Merewether, C. (2006). Introduction. In C. Merewether (Ed.), The Archive (pp. 10-17). Cambridge, MA: The MIT Press.

Mulligan, S. (2011). Lost in history: Student artists experience the archives. Journal of The Society of North Carolina Archivists, 9(1), 46-49.

Post, C.C. (2017). Ensuring the legacy of self-taught and local artists: A collaborative framework for preserving artists' archives. Art Documentation: Bulletin of The Art Libraries Society of North America, 36(1), 73-90. Retrieved from https://doi.org/10.1086/691373 
Schreiner, M., \& de los Reyes, C.D. (2016). Social practice artists in the archive: Collaborative strategies for documentation. Urban Library Journal, 22(2), 1-8. Retrieved from https://academicworks.cuny.edu/ulj/vol22/iss2/1

Stinson, A.D., Fauconnier, S., \& Wyatt, L. (2018). Stepping beyond libraries: The changing orientation in global GLAM-Wiki. JLIS.It, Italian Journal of Library, Archives \& Information Science, 9(3), 16-34. Retrieved from https://www.jlis.it/article/view/12480

Wilson, F., Corrin, L. G., \& Contemporary (Baltimore, Md.). (1994). Mining the museum - an installation by Fred Wilson. Baltimore, Md.: The Contemporary.

Windon, K. (2012). The Right to decay with dignity: Documentation and the negotiation between an artist's sanction and the cultural interest. Art Documentation: Bulletin of the Art Libraries Society of North America, 31(2), 142-157. Retrieved from https://doi.org/10.1086/668108

Zaatari, A. (2006). Photographic documents/ Excavation as art. In C. Merewether (Ed.), The Archive (pp. 181-184). Cambridge, MA: The MIT Press.

Zanella, F., Bignotti, I., Modena, E., \& Scotti, M. (2015) MoRE, an archive of signs and traces of artistic practices: creating a tool for research in contemporary art and curatorial practices. Archives \& Records. 36(1), 5670. Retrieved from https://doi.org/10.1080/23257962.2015.1015260 